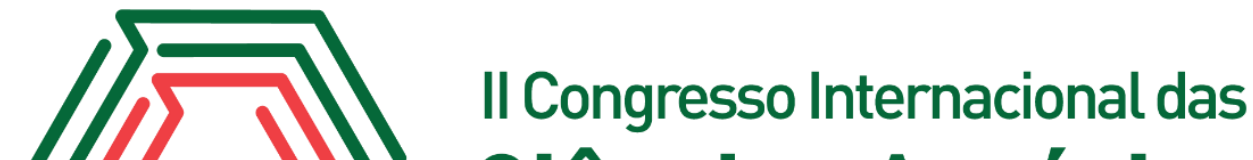 Ciências Agrárias COINTER - PDVAgro 2017
}

\section{PROPOSTA PARA IMPLEMENTAÇÃO DE ÁREA SILVIPASTORIL NO CARIRI CEARENSE}

Dyovana Silva Pontes ${ }^{1}$; Brisa do Svadeshi Cabral de Melo ${ }^{2}$

\section{Introdução}

A preservação ambiental suscita um grande entendimento mundial de que a buscas incessantes por novas técnicas de convivência simbiótica entre o homem e a natureza são necessárias. As pesquisas nesse âmbito têm tomado grandes proporções para tornar a pecuária e a agricultura cada vez mais adequada às leis ambientais, devido uma maior importância a temas como sustentabilidade e bem estar animal. O Sistema Silvipastoril surge como uma alternativa cada vez mais adotada entre produtores, visando à viabilidade econômica atrelada à biodiversidade na propriedade rural.

Sistemas Silvipastoris constituem um modelo agroflorestal, que combinam plantas forrageiras, árvores e animais em uma mesma área, por meio da conservação e da manutenção da vegetação previamente existente e pelo plantio ou pela condução da regeneração da vegetação natural, promovendo também a cobertura do solo, que amenizam o intemperismo químico e físico. No campo de produções pecuárias, os Sistemas Silvipastoris vêm sendo adotados como alternativas para recuperação de áreas de pastagens degradadas, ocasionando condições favoráveis aos animais, como conforto térmico, pastejo diversificado e consequentemente uma intensificação da produção (ALMEIDA et al.,2014; ALVES et al., 2014).

Objetivou-se nesse trabalho demonstrar a viabilidade de uso destes Sistemas no semiárido brasileiro e destacar o Cariri Cearense como potencial produtor em um Sistema Silvipastoril.

\footnotetext{
1 Graduanda em Zootecnia, Instituto Federal de Educação, Ciência e Tecnologia do Ceará IFCE-campus Crato, dyovanapontees@gmail.com

2 Doutora em Agronomia/Fitotecnia, Instituto Federal de Educação, Ciência e Tecnologia do Ceará IFCE- campus Crato, brisa.cabral@gmail.com
} 


\section{Fundamentação Teórica}

A Caatinga, vegetação dominante no semiárido brasileiro, vem sofrendo intenso processo de degradação, provocado, entre outras causas, pelas atividades agropecuárias e extrativistas má conduzidas. A necessidade de conservar o meio ambiente e seus recursos naturais ocasionou a busca por alternativas. O Sistema Silvipastoril surge com a finalidade de explorar, de forma ecológica, espécies arbustivo-arbóreas e pastagens em uma mesma área física. (CAMPANHA et al., 2011).

A Chapada do Araripe, onde está localizado o Cariri Cearense, é formada por um mosaico vegetacional, onde coexistem manchas de floresta ombrófila e estacional, cerrado, caatinga e carrasco, resultantes da heterogeneidade ambiental. Todas as condições climáticas intrínsecas à região do Cariri Cearense é diretamente condicionada pela Chapada, uma vez que seu relevo interage com as massas de ar, proporcionando um clima relativamente ameno em relação ao entorno semiárido (GEOPARK, 2014).

As atividades econômicas da região estão atreladas à exploração dos recursos madeireiro da floresta, sendo este a principal fonte energética da região, com ênfase na madeira extraída da Caatinga. Associado à demanda energética de madeira para a exploração está à necessidade de plantas forrageiras para atender às necessidades da pecuária regional. Para isso, o Sistema Silvipastoril, surge com o intuito de implementar florestas energéticas, consorciadas com espécies arbóreas de rápido crescimento e forrageiras, adaptadas ao clima, visando garantir a estabilidade da produção e elevar a produtividade, melhorar a fertilidade do solo e aumentar a oferta de forragem de boa qualidade (DRUMOND et al, 2010).

A vegetação nativa do semiárido é ricamente diversificada, com muitas espécies forrageiras nos três estratos: herbáceo, arbustivo e arbóreo. Estudos comprovam que mais de $70 \%$ das espécies da caatinga participam da dieta dos ruminantes domésticos (GOIS et al., 2017; ANDRADE et al., 2012). Esse fato ganha maior importância na estação seca, quando aumento da disponibilidade de folhagem seca das árvores e arbustos, tornam-se relevantes ingredientes na dieta, principalmente de caprinos (SILVA et al., 2010).

Autores como Estremote et al (2015), afirmam que criações de pequenos ruminantes como caprinos e ovinos são altamente vantajosas em um Sistema Silvipastoril, proporcionando um 
ecossistema em equilíbrio, gerando diversos benefícios, como conforto térmico aos animais, e também melhora no desempenho produtivo.

\section{Metodologia}

Para o desenvolvimento da proposta, foi mapeada uma área localizada no Instituto Federal de Educação, Ciência e Tecnologia do Ceará - IFCE campus Crato, localizado no Bairro Gisélia Pinheiro KM 15 na CE 292, no Município de Crato no Cariri Cearense, no entorno da Chapada do Araripe. A área mapeada é de $12.275 \mathrm{~m}^{2}$, altitude $612 \mathrm{~m}$, coordenadas geográficas latitude $7^{\circ} 12^{\prime}$ 29.97” S e Longitude $39^{\circ} 26^{\prime} 47.28$ O. O solo se classifica como Latossolo, com condições climáticas subúmidas e com regime de chuvas irregulares onde a quadra chuvosa vai de fevereiro à junho, com índices pluviométricos até 700mm/ano (GEOPARK 2014). As temperaturas médias situam-se entre $23^{\circ} \mathrm{C}$ e $27^{\circ} \mathrm{C}$.

O levantamento de dados foi executado através de atividade de campo, onde foi constatada uma análise observatória das plantas com potencial forrageiro que possam ser utilizadas na dieta de pequenos ruminantes. Todas as plantas foram identificadas com placas de madeiras com o nome popular, próximo à raiz, para pesquisas seguintes. Foi feita uma seleção bibliográfica especializada em espécies arbustivo-arbóreas forrageiras, nativas e exóticas, onde se realizou um estudo com respeito ao conhecimento científico sobre o tema, destacando o potencial das plantas encontradas e a sua utilização na alimentação de pequenos ruminantes.

\section{Resultados e Discussões}

O presente trabalho apresentou como resultado a viabilidade da implementação da área Silvipastoril, evidenciando a riqueza botânica da variabilidade de espécies forrageiras encontradas (Tabela 1), com destaque para as arbóreo-arbustivas nativas e exóticas, com características de pastejo de caatinga presente no semiárido. Apesar disso, planeja-se a inserção de outras espécies, visto que uma maior diversidade promove um maior equilíbrio para área e uma segurança alimentar. 
Tabela 1: Relação das famílias e espécies da área mapeada para um Sistema Silvipastoril. Fonte Própria

\begin{tabular}{|l|l|}
\hline \multicolumn{1}{|c|}{ Família } & Espécies (Nome popular) \\
\hline Capparaceae & Capparis flexuosa L.(Feijão-bravo) \\
\hline Chrysobalanceae & Licania tomentosa Benth. (Oiti) \\
\hline Euphorbiaceae & Croton banchetianus Baill. (Marmeleiro) \\
\hline Fabaceae & $\begin{array}{l}\text { Enterolobium contortisilium Vell. (Timbaúba) } \\
\text { Prosopis juliflora } \text { Sw. (Algaroba) } \\
\text { Leucaena leucocephala } \text { Lam. (Leucena) }\end{array}$ \\
\hline Leguminosae (Caesalpinoiedeae) & Caesalpinia férrea Mart. (Pau ferro) \\
\hline Leguminosae (Mimosoidae) & Mimosa caesalpiniifolia Benth. (Sabiá) \\
\hline Malvaceae & Guazuma ulmifolia Lam. (Mutamba) \\
\hline Polygonaceae & Coccoloba latifólia Lam. (Coaçu) \\
\hline Rhamnaceae & Zyzyphus joazeiro Mart. (Juazeiro) \\
\hline Solanaceae & Solanum inodorum Vell. (Cipó branco) \\
\hline
\end{tabular}

O manejo da pastagem em Sistemas Silvipastoris deve ser mais criterioso, pois as forrageiras encontram-se em grau de competição com o componente arbóreo mais elevado. Neste sentido, deve-se procurar manter a altura de pastejo indicada para cada cultivar, para permitir maior acúmulo de reservas e favorecer a rebrotação (ALMEIDA et al., 2014). Nesse caso á área adotada necessita de manejo adequado para que ocorra o desenvolvimento mais proveitoso, podendo utilizar de raleamento e poda do componente arbóreo estabelecidos na área.

Algumas espécies da caatinga também podem ser manejadas para a produção de madeira e forragem (ALMEIDA et al.,2014). Carvalho et al (2004), realizaram um experimento em Sistema Silvipastoril onde o rebaixamento do sabiá (Mimosa caesalpinifolia) e a preservação do crescimento de dois fustes com o rebaixamento do restante, permitiu a redução de 15 para 7 anos o tempo para extração de madeira. Além disso, observou-se que a oferta de folhas das rebrotações ficou presente por mais de sessenta dias após o término das chuvas, sendo importante fonte de alimentação para os rebanhos na Caatinga. Para a área estudada nesse trabalho, o manejo citado é perfeitamente conveniente, pois a mesma está ricamente composta por sabiá (Mimosa caesalpinifolia).

\section{Conclusões}


A busca por novas técnicas de produção de alimento têm despertado considerável interesse na comunidade científica, em razão da necessidade de se aprimorar métodos sustentáveis. Com isso uma área experimental nesse quesito numa região como o Cariri Cearense é totalmente propícia, criando novas alternativas de exploração agrícola aliada às questões ambientais e também contribuindo para ampliar pesquisas.

\section{Referências}

ALMEIDA, R. G.; RANGEL, J. H. A.; RODRIGUES, A. C. C.; ALVES, F. V.; Sistemas silvipastoris: produção animal com benefícios ambientais. In: IX CONGRESSO NORDESTINO DE PRODUÇÃO ANIMAL 2014. Ilhéus- BA.

ALVES, F. G. S.; FELIX, B. A.; PEIXOTO, M. S. M.; SANTOS, P. M.; COSTA, R. B.; SALES, R. O.; Considerações sobre manejo de pastagens na região semiárida do Brasil: Uma Revisão. Revista Brasileira de Higiene e Sanidade Animal, v.8, n.4, p.259-283, out-dez, 2014.

ANDRADE, C. M. S.; SALMAN, A. K. D.; OlIVEIRA, T. K. Guia Arbopasto: manual de identificação e seleção de espécies arbóreas para sistemas silvipastoris. Brasília: Embrapa, 2012. $345 \mathrm{p}$.

CAMPANHA, M. M.; ARAÚJO, F. S. MENEZES, M. O. T.; SILVA, V. M. A.; MEDEIROS, H. R.Estrutura da comunidade vegetal arbóreo-arbustiva de um sistema agrossilvipastoril, em SobralCE Revista Caatinga, Mossoró- RN, v. 24, n. 3, p. 94-101, jul.-set.2011.

CARVAlHO, F. C. C.; GARCIA, R.; ARAÚJO FILHO, J. A. et al. Manejo in situ do Sabiá (Mimosa caesalpinifolia Benth.) para produção simultânea de madeira e forragem em um sistema silvipastoril. Agrossivicultura, v.1, n.2, p 121-129, 2004.

DRUMOND, M. A.; RIBASKI, J.; SÁ, I. B.; NASCIMENTO, C. E. S.; OLIVEIRA, V .R. Espécies arbóreas exóticas de uso múltiplo para o Semiárido brasileiro. In: Semiárido Brasileiro: Pesquisa, Desenvolvimento e Inovação. Petrolina: Embrapa Semiárido, 2010 cap. 7, pág.246.

ESTREMOTE, M.; MELO, V. F. P.; PINHEIRO, R .S .B . Sistema silvipastoril na produção de ovinos. XI FÓRUM AMBIENTAL DA ALTA PAULISTA, v. 11, n. 2, pp. 219-227.2015.

Geopark Araripe. "Clima”. geoparkaraipe.org.br. Disponível $<$ http://geoparkararipe.org.br/clima/ $>$ Acesso: 06 de Setembro de 2017.

GOIS, G. C.; CAMPOS, F. S.; CARNEIRO, G. G.; SILVA, T. S.; MATIAS, A. G. S.; Estratégias de Alimentação para caprinos e ovinos no semiárido brasileiro. Nutri Time, Vol.14, $\mathrm{N}^{\circ}$ 04, jul/agos 2017.

SILVA, N. V.; COSTA, R. G.; FREITAS, C. R. G.; GALINDO, M. C. T.; SILVA, L. S. 2010. Alimentação de ovinos em regiões Semiáridas do Brasil. Acta Vet. Bras. 4:233-241. 